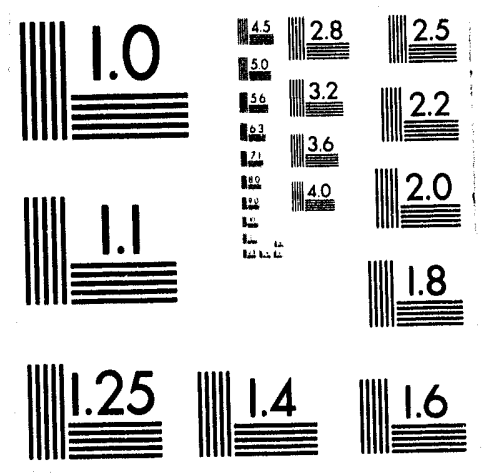



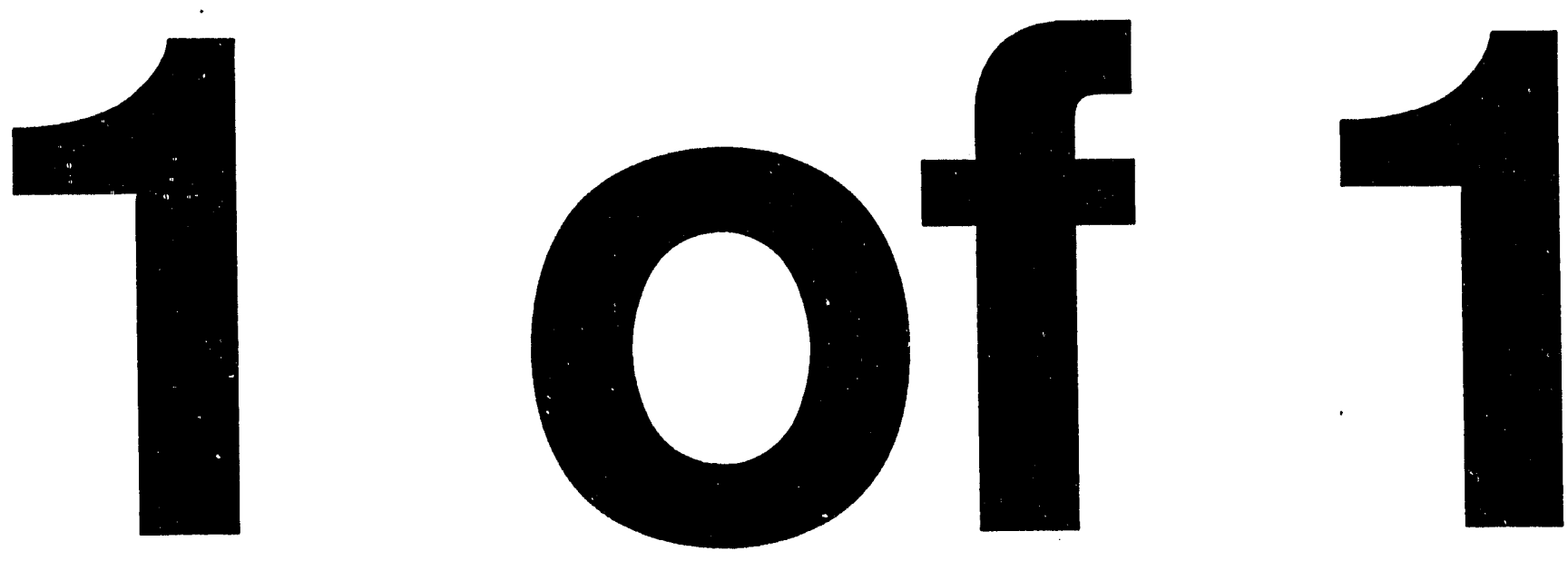
TECHNICAL PROGRESS REPORT

$\begin{array}{lll}\text { Date } & : & \text { November 6, } 1991 \\ \text { Report No. : } & \text { TPR-34 } \\ \text { Reporting Period: } & \text { July - September } 1991\end{array}$

CONTRACT TITLE AND NUMBER: Advanced Coal-Fueled Gas Turbine Systems DE-AC21-86MC23167

CONTRACTOR'S NAME:

\author{
Westinghouse Electric Corporation \\ Strategic and Business Development \\ 4400 Alafaya Trail \\ Orlando, FL 32826-2399
}

NOTICE

This report was prepared as an account of work sponsored by an agency of the United States Government. Neither the United States nor any agency thereof, nor any of their employees, make any warranty, expressed or implied, or assumes any third party's use or the results of such use of any information, apparatus, products or process disclosed in this report or represents that its use by such third party would not infringe privately owned rights.

This document copy, since it is transmitted in advance of patent cleprance, is made avaifable in cpnfidence solely for yse in performance of work under contracts with DOE/Morgantown Energy Techholdgy Center. This decument is hot to be puplished nor its contents otheywise disseminated of used for purposes other than specified qbove before patent approval for such release or use has been secured, upon request, from the officel of Patent Coundi1, US/DOE, P.O. Box E, Oak Ridge, Tennessee 37830. 


\subsection{SUMMARY}

During June, July and the beginning of September five slagging combustor tests (CR1-2 through CR1-6) were conducted. Since integrating the slagging cyclone separator into the combustor system, noticeable quantities of char have been collected in the cycione slag bucket and detected in the exhaust gases. The primary purpose of the CR1-X series of tests was to quantify the amount of char produced by the subscale slagging combustor system. The secondary purpose of this test series was to quantify the slag separation efficiency of the curved body impact separator and to acquire more information on the operation of the slagging cyclone separator.

Test CR1-1, performed in June 1991, was conducted with a fully configured system, i.e., the curved body impact separator, slag tap bath, and slagging cyclone were installed. The CR1-1 data constitutes a baseline for the char production problem. For test CR1-2, the curved body impact separator and slag tap were removed and the centerbody impact separator was installed. This was done to recheck the relative influence of the curved body impact separator and slag tap bath on char production; also, to acquire additional data on the slag collection efficiency of the centerbody impact separator and slagging cyclone. The latter was used for deducing accurately the collection efficiency of the curved body impact separator. Qualitativeiy, the results of test CR1-2 suggested that the curved body impact separator and slag tap bath components do not influence char production significantly.

The efficiency of the centerbody impact separator was determined to be about $90 \%$, which is consistent with previous measurements. The efficiency of the slagging cyclone could not be determined because the particulate matter exhausted from the system could not be determined. This was because the downstream particle probe filter broke during the run. The slagging cyclone efficiency is derived by measuring the overall particulate collection efficiency (particle probe) and the efficiency of the centerbody impact separator.

Based on the results of the CR1-X tests conducted, 2-3\% (wgt) of the coal is not being burned-out, resulting in the observed char. Several mechanisms for 
the occurrence of char subsequent to the integration of the slagging cyclone are possible. Current thinking suggests that elevation of the system for the purpose of cyclone integration may have upset the distribution of coal to the four coal/air injectors issuing into the primary zone. This could lead to spatial non-uniformities in primary zone stoichiometry, which could lead to char production. A preliminary review of slag separation efficiency data implies that the curved body impact separator efficiency is only slightly degraded relative to the centerbody impact separator efficiency.

Upon completion of the char tests, a meeting involving senior Textron staff and combustion facility personnel was held to review the results. In September Textron began video taping the combustion process at the top of the primary zone. The tape of the first test during September showed that unsteady combustion may be occurring. Arguments were presented at the meeting that suggest the unsteadiness may be traceable to unsteady coal delivery to the primary zone coal/air injectors. It was hypothesized that the coal delivery system may have been marginally stable before elevation of the combustor system and installation of the cyclone, and that these changes, which added pressure losses, may have lead to unstable coal delivery behavior. Although the next phase of testing focused on optimizing sulfur capture, system modifications that have potential for reducing char production were effected as they were formulated. Reducing char production should yield greater sulfur reduction by virtue of improved combustion and higher primary zone temperatures.

In the first two sulfur capture test runs, sorbent injection was varied to achieve calcium-to-sulfur molar ratios in the range of 2-4. Sulfur reductions in the range 30 to $50 \%$ were measured, but these results may not be valid since a substantial water cooling leak developed in the curved body separator. It has been hypothesized that the Magnetite diluent being mixed with the limestone sorbent is significantly reducing the protective slag layer on the curved body impact separator. This could increase heat transfer rates on this element significantly, leading to thermal stresses that may crack weld seams. Since extremely good slag flow is being achieved during sorbent 
injection with this sorbent mixture, lower concentrations of Magnetite sorbent diluent will be used in future runs in order to prevent stripping the impact separator of its insulating slag layer.

Prior to the second sulfur capture test, temporary coal delivery system changes were made that showed promise for stabilizing coal delivery to the coal/air injectors. The inside diameters of all hoses on the coal delivery system were decreased in order to achieve higher coal conveying velocities, which in turn should have stabilized the coal delivery flow. Upon initiating coal combustion during this run, the air carrier mass flow rate dropped to zero and the pressure head in the coal tank drove a very dense phase coal flow through the delivery system to the coal/air injectors. Coal combustion occurred for a few minutes, but eventually ceased due to plugging somewhere in the coal delivery system. The stalling of the carrier air was due to the fact that the carrier air compressor did not have a pressure head high enough to overcome the increased pressure drop caused by the smaller ID hoses installed in the coal delivery system. This result was not unexpected and either a higher pressure compressor system or an air tube trailer will be rented and installed prior to future tests to supply the air and pressure head needed to achieve the desired carrier air flow rates.

\subsection{TECHNICAL PROGRESS}

\subsection{Subscale Combustion System.}

\subsubsection{Char Quantification Tests}

\section{Test CR1-2}

CR1-2 was the second char quantification test conducted. The system was reconfigured for this run. The curved body impact separator and slag tap bath were removed and the centerbody impact separator was installed. During this test, 512 pounds of fresh Dorchester coal were burned. The length of the coal combustion portion of the run was 44 minutes. The equivalence ratio was nominally $\phi=1.2$. 
The primary reason for installing the centerbody impact separator was to verify that the curved body impact separator and slag tap bath components were not causing the char production problem. It was thought that the latter components could have been causing a flow oscillation to feed back into the primary zone which may have been causing the coal injection jets to oscillate, resulting in coal issued directly to the exit of the primary zone. Similar tests were conducted earlier this year, but were repeated for two reasons. The first reason related to the operation of the downstream particulate sampling probe, which has been changed. The probe now is not being back purged until steady coal combustion is achieved. The purge flow is then stopped and exhaust gases are allowed to flow through it. The flow through the probe is stopped just before coal combustion is halted. The amount of coal burned during sampling and sampling elapse time are recorded. This mode of operation was adopted in order to make certain that startup and shutdown transients do not load the particle filter with significant amounts of particulate matter. The former mode of operation allowed the particulate probe to sample all of the time. The second reason was that a systematic approach towards identifying the cause of char carryover was adopted.

It has been found that determining the collection efficiency of the curved body impact separator via component weight differences and collected or removed slag is not very accurate. The curved body impact separator configuration requires too many weights to be measured. The collection efficiency of the curved body impact separator can be deduced with a greater degree of accuracy by deriving it from total collection efficiency and slagging cyclone efficiency. Total collection efficiency is determined from particle collection measurements via the downstream particle collection probe. The collection efficiency of the slagging cyclone is best derived from overall collection efficiency and the efficiency of the centerbody impact separator. The collection efficiency of the centerbody impact separator is determined via the difference in centerbody impact separator housing weight, as measured before and after a test run. Thus, a secondary reason for installing the centerbody impact separator was to verify the separation efficiency of the centerbody impact separator and the slagging cyclone separator. 
The weight change in centerbody impact separator housing for test CR1-2 was 33 1bs. The total coal burned was 612 lbs, which contained 38 lbs of ash. The measured collection efficiency of the centerbody impact separator is, therefore, $87 \%$. This is consistent with previous results. The efficiency of the slagging cyclone could not be derived because the overall collection efficiency measurement failed. The overall collection efficiency is determined via the weight increase of the particle collection probe filter, which broke sometime during the test.

The total amount of slag/char collected by the slagging cyclone bucket was 23 lbs for test CR1-2. This material was sent out to have it separated into slag and char. Once separated, the weight of the char was used to quantify the char production for the centerbody impact separator, slagging cyclone configuration. These results are discussed under Section 2.1.2.

By applying proximate analysis to the material collected by the particle collection probe, the ash/carbon weight ratio for material exhausted from the system can be determined. This, together with the total amount of ash and char exhausted from the system, would give the total amount of unburned coal passing all the way through the system. The total amount exhausted is also determined from particle collection probe filter weight increase measurements. The exhausted amount of unburned coal plus the char collected in the cyclone bucket will give the total amount of unburned coal, thus carbon conversion and quantification of the char problem.

\section{Test CR1-3}

CR1-3 was the third char quantification test conducted. The system was operated with the centerbody impact separator installed. A new diagnostic was added to the system which provides a real-time indication of exhaust gas particle loading (see Helium-Neon Laser Diagnostic Addition, Section 2.1.4). During this test run, 658.5 pounds of Dorchester seam coal were burned. The coal burned during this run was from the first new shipment received in June 1991. The duration of the coal combustion segment of this run lasted 47 minutes. This test run was performed operating at an equivalence ratio of $\phi=1.2$. No sorbent was injected during this run. Weights of the slag 
collected in the impact separator and cyclone were acquired. The slag/char mixture in the cyclone bucket was separated and weights for each was obtained. Slag samples from these components were sent out for elemental analysis, so that the amount of char entrained in the slag and collected by the impact separator housing and slagging cyclone could be determined. This data had not been received prior to the end of this reporting period.

During this test a hole formed in the particle probe filter and it was not possible to directly determine the amount of char and ash exhausted from the system. Using the He-Ne extinction diagnostic data, the elemental analysis and particle filter results from other test runs, a reasonably accurate estimate of the exhausted char and ash for this run was possible. The char production results are discussed in Section 2.1.2 under Char Production.

The secondary goal of the char quantification test sequence was to determine the slag removal efficiencies of the impact separators and the slagging cyclone. Since the amounts of slag collected by the centerbody impact separator and slagging cyclone are available from the char production analysis, it was possible to derive preliminary efficiency results, which will be refined when the elemental analyses results are received for the samples sent out for analysis. The preliminary slag collection efficiency results are discussed under Section 2.1.2.

\section{Test CR1-4}

CR1-4 was the fourth char quantification test conducted. The system was operated with the centerbody impact separator installed. The new HeNe extinction diagnostic was used during this run and is expected to become a standard diagnostic for the system. During this test run, 684.5 pounds of new Dorchester seam coal were burned. The duration of the coal combustion segment of this run lasted 49 minutes. This test run was performed operating at an equivalence ratio of $\phi=1.2$. No sorbent was injected during this run. This test was the same as CRI-3 and the same types of data collected and associated procedures for this test were used as for test CR1-3. 
From an operational point of view test CR1-4 was not as smooth a run as CR1-3. Two difficulties were encountered, one occurring at the start of this run, the other detected after this run. When coal combustion was attempted at the beginning of CR1-4, no coal combustion took place when the coal flow was started. The system was shutdown and possible causes investigated. It was found that a leak had opened up at the junction of the coal carrier line and coal storage tank. A very small amount of pulverized coal was discharged onto the floor. The seal at this junction had developed a small leak and was responsible for the failed coal combustion attempt. Once fixed, the remainder of the run proceeded smoothly. After completing this run, it was discovered that one of the particle collection probe filters that had failed during the last two test runs had failed again (i.e., the ceramic filter had developed a hole). The hole develops because a 1/8" diameter bar applies a sma11 amount of pressure on one end of the filter that holds the filter in its seat. Apparently there is enough vibration, either from the gas flow through the filter housing or from mechanical vibration, to cause this bar to chafe the end of the ceramic filter, eventually causing breakthrough. The housing for this filter was reworked to eliminate this problem.

\section{Test CR1-5}

Test CR1-5 was the fifth char quantification test conducted. The system was reconfigured by replacing the centerbody impact separator with the curved body impact separator and slag tap/bath components. During this test run 711.5 pounds of new Dorchester seam coal were burned. The duration of the coal combustion segment of this run lasted 51 minutes. This test run was performed operating at an equivalence ratio of $\phi=1.2$. No sorbent was injected.

The main purposes of this test were the same as for test CR1-3. The only difference being that data was acquired to evaluate the behavior of the new system configuration. Specifically, the purpose of this test was to: 1) acquire data to quantify combustor char production with the curved body separator, slag/tap bath in place and 2) acquire data to quantify the slag collection efficiencies of the curved body impact separator, slag tap/bath, and slagging cyclone. These test results are discussed under the Section 2.1.2, titled Results of Char Quantification Tests CR1-1 through CR1-6. 
An additional goal was added for test run CR1-5. It was noticed after the last run (CR1-4) that some of the hoses from the coal splitter to the four primary zone coal/air injectors had different end-fittings than the others. Further inspection revealed that two of the hoses had end-fittings that had a cross-sectional area twice that of the end-fittings on the other two hoses. A factor of two area difference could produce an increased flow of coal to two of the coal/air injectors and reduced flow to the other two. This would cause half of the dome region of the combustor to run extremely fuel-rich, thus producing char, while the other half of the dome would run fuel-lean. These hoses were modified so that all end fittings, as well as their lengths, were all the same. The exits of the coal delivery tubes inside the coal/air injectors were moved halfway up the air passages of the coal/air injectors at this time. Before this, the coal delivery tubes were discharging coal into the primary air at the entrance of the air passages in the injectors.

The entrance region of the air passages is a highly disturbed flow region, which could have been biasing the dispersion of the coal to the underside of the resulting coal/air jets. This would provide a path for coal to be directed to the exit of the combustor once the coal/air jets were injected into the primary zone. Unfortunately, no change in char production was detected as a result of these changes. A noticeable increase in primary zone CO levels (roughly 2\%) was detected. Even though these modifications did not remove the char problem, the change in $\mathrm{CO}$ levels suggested that coal injection behavior was a possible candidate for inspection in subsequent runs. More specifically, when the system was elevated to allow for installation of the slagging cyclone, the coal splitter was elevated also. This additional increase in height may be effecting the uniformity of coal distribution to the four coal/air injectors, which could lead to non-uniform primary zone stoichiometry.

From an operational point of view test, CR1-5 was a reasonably smooth run. Only one difficulty was encountered, which occurred at the start of this run. During initiation of the coal combustion segment of this test, the coal flow rate was started at a rate lower than desired (i.e., coal combustion was initiated fuel-lean). The reason for this was to ensure complete carbon burnout while the system was coming up to operating temperature. If the coal flow 
rate jumps up to the operating flow rate during coal combustion initiation, poor carbon burn-out occurs. This occurred during the startup of the coal combustion segment of this run. Also, good slag flow at the tap did not occur as early as it should have. For this reason, the distribution of slag among the various components of the system changed. Weights of slag in the various components was different than what was measured in the next run CR1-6. Regarding the particle collection probe filters that failed during the previous three runs, both filters survived this run intact. The fix applied to the particle filter problem seems to have eliminated filter failures.

\section{Test CR1-6}

This was the sixth and last char quantification test in the test series CR1$X$. The system was operated with the curved body impact separator and slag tap/bath installed. During this run 863 pounds of Dorchester seam coal were burned. The duration of the coal combustion segment of the run lasted 62 minutes. This test run was performed operating at an equivalence ratio of $\phi=1.2$. No sorbent was injected during this run. No unusual behavior was experienced during this run.

\subsubsection{Results of Char Quantification Tests CR1-1 Through CR1-6.}

Preliminary results are given in the discussions that follow. They are based on incomplete information and should be regarded as tentative until they are refined based on complete information. Refinement of char production results and component slag capture efficiencies will require proximate and uitimate analyses of the coals burned and elemental analyses of slag and char samples from several points in the system. Samples were sent out for analys is in September for tests CR1-1 through CR1-6. Refined results, based on the results of these analyses, probably will not be available until December 1991.

\section{Char Production}

The char production results given in Table 1 for the centerbody impact separator configuration, based on tests CR1-2 through CR1-4, are an average over these three runs. Test CRI-1 was not used for char production 
quantification because it was a transition run, meaning that Pittsburgh No. 8 coal was burned during the run prior to CR1-1, whereas Dorchester seam coal was burned during CR1-1. It is a good practice to allow one run on a new coal in order to purge the system of slag from the prior coal before making quantitative measurements. The char production results for the curved body impact separator, slag tap/bath configuration, based on tests CR1-5 and CR1-6, are an average over these two runs.

The lower bound on char production is based only on the amount of char collected in the cyclone bucket. The upper bound is based on the cyclone bucket char, plus an estimate of the total amount of particulate material exhausted from the system. It should be noted that neither of these bounds includes char that may have been entrained in the slag. Estimates for the amount of char entrained in the slag will be available once slag sample analyses have been received. Updated char production results will be provided once this information is avallable. The char production results, given in Table 1 for the two different system configurations, are expressed as a fraction of the total coal burned.

$$
\begin{aligned}
& \text { Centerbody Impact Separator Configuration } \\
& \text { (Avg for Tests CR1-2 to CR1-4) } \\
& \begin{array}{ll}
\text { Lower Bound } & 2.3 \% \text { (wgt) } \\
\text { Upper Bound } & 3.0 \% \text { (wgt) }
\end{array}
\end{aligned}
$$

Curved Body Impact Separator Configuration

(Avg for Tests CR1-5 to CR1-6)

$\begin{array}{ll}\text { Lower Bound } & 1.6 \% \text { (wgt) } \\ \text { Upper Bound } & 2.4 \% \text { (wgt) }\end{array}$

Table 1. Char Production Results 
As can be seen in Table 1, approximately 2-3\% by weight of the coal is not being coriverted. The results should not be interpreted to imply that different system configurations lead to differences in char production rate, rather the differences should be interpreted as the accuracy of the derived results.

\section{Component Slag Separation Efficiencies}

In order to definitize the slag separation efficiencies of the centerbody and curved body impact se, arators and the slagging cyclone, the amount of char entrained in the slag must be known, as well as the amount of char and ash exhausted from the combustor system. Samples of the slag from relevant points in the system and of material collected in the exhaust section particle probe filters were sent out for elemental analysis during September. Until receipt of the results of these analyses, definitization of the separation efficiencies of the impact separators and slagging cyclone cannot be realized.

A very rough, preliminary analysis has been applied, however, to the weights of slag collected by the impact separators and slagging cyclone that gives one important result. If the total weight of the slag introduced during a given run by the burned coal is assumed to be the sum of the slag collected by the impact separator and the slagging cyclone, then the relative efficiency of the impact separator and cycleno can be estimated by normalizing their individual weights by the assumed total weight. Since very little ash is exhausted from the combustor system, the total weight of the slag introduced during a run can be estimated this way with reasonable accuracy, provided the slag does not contain a significant amount of char.

When this procedure was followed, it was found that the efficiency of the curved body impact separator was only slightly degraded relative to the centerbody impact separator. This qualitative result regarding impact separator slag separation efficiency is the only one which can be presented at this time. Further statements will have to await receipt of the elemental analysis being performed on slag and particle filter samples. 


\subsubsection{Sulfur Capture Tests}

\section{Test SL2-1}

Two sulfur capture test sequences were planned for 1991. The first sequence, designated SL1-X, consisted of test runs SL1-1 through SL1-3, which were performed during June. Sulfur capture testing was suspended during July and August in order to perform char quantification test runs.

Test SL2-1, run on September 19, was the first sulfur capture test to be performed from test sequence SL2-X. The system was operated with the curved body impact separator and slag tap/bath installed; 852 pounds of Pittsburgh No. $8 \mathrm{coal}$ were burned. The duration of the coal combustion segment of the run lasted 61 minutes. This test run was performed operating at an equivalence ratio of $\phi=1.2$. Sorbent was injected during the later part of the coal combustion segment of the run. The sorbent was a 1:1 mixture (by weight) of limestone and Magnetite. During the sulfur capture test, 91 pounds of the sorbent mixture were injected into the primary combustor. The total duration of the sulfur capture test was 14 minutes. Sorbent flow rates of 4 , 6 , and 8 pounds per minute were achieved, which correspond to $\mathrm{Ca} / \mathrm{S}$ molar ratios of $1.9,2.8$, and 3.7 , respectively.

System behavior prior to sorbent injection was good, except for the usual p:oduction of char, which was monitored via the He-Ne extinction diagnostic. The behavior of the sorbent injection system during sulfur capture testing was excellent. Smooth control of sorbent flow rate was easily achieved. This has been achieved by: 1) diluting the limestone sorbent, which has poor pneumatic conveying properties, with Magnetite which has good pneumatic conveying properties, 2) agitating the sorbent mixture at the exit nozzle of the sorbent hopper via cyclic injection of Nitrogen gas through an array of nozzles in the exit nozzle of the sorbent hopper, and 3) applying proper filtering to the sorbent flow rate readout unit.

Five minutes after initiating sorbent injection, however, a cooling water leak developed in the curved body impact separator. The leakage of cooling water into the impact separator housing was substantial. Although sulfur capture 
levels ranging from 30 to 50 percent were measured in the combustor exhaust gas stream, the measured sulfur capture levels should not be taken as trustworthy. This is because the leak introduced large amounts of water vapor into the exhaust stream being sampled for $\mathrm{SO}_{\mathrm{X}}$. Since it is not known if sample line dryers removed all the water vapor, it is possible that some $\mathrm{SO}_{2}$ /water reactions may have occurred in the sample lines before reaching our analyzers. The curved body impact separator cooling water leakage occurred only once before. The leak, however, seems to occur just after initiating sorbent injection. It is suspected that the sorbent diluent (i.e., Magnetite, which is an effective fluxing agent for reducing slag viscosity) is removing a substantial amount of the slag layer on the curved body separator, thereby changing heat transfer rates significantly. This phenomena could be generating thermal stresses that cause welded seams to crack. The curved body impact separator leak was easily fixed by rewelding the cracked seam. It was determined that sorbent mixtures containing less Magnetite would be used in future tests to reduce the effects of this fluxing agent on impact separator integrity.

\section{Test SL2-2}

Test SL2-2, conducted on September 26, was to be the second sulfur capture test performed from test sequence $S L 2-X$. However, this run was a combined sulfur-capture/char-reduction test. A meeting among test facility personnel and Textron senior staff scientists took place on September 16 to review the results of the char test sequence, i.e., sequence (RI-X).

During test CR1-6, a video camera was positioned so that it was viewing combustion occurring at the top of the primary zone. This tape was reviewed during the meeting mentioned above, where it was concluded that primary zone combustion appeared to be unsteady. During test CR1-6, the four coal injector delivery tubes were repositioned inside each coal/air injector passage to see if this had an effect on char production. The coal carrier line from the coal tank to the four-way coal splitter was elevated before beginning test CR1-6 in order to see if changes in splitter elevation could effect coal delivery behavior. (It should be noted that the entire combustor, including the coal splitter, was elevated by nominally 30 inches when the cyclone was installed 
and that the char problem appeared after installation of the cyclone.) Repositioning the coal delivery tubes in the coal/air injectors and raising/ lowering the coal carrier line between the coal tank and splitter did not change char production rates during CR1-6. However, every time a coal delivery system element was moved, a noticeable change in coal flow rate was observed. This observation implies that the stability of the coal delivery system may be marginal, if not unstable. This instability could be responsible for the unstable combustion observed in the primary zone combustion video, and could lead to char production.

As a result of the September 16 meeting, it was decided to change the coal delivery system in such a way as to improve coal flow stability. After determining the actual flow velocities in the lines conveying the pulverized coal from the coal tank to the coal/air injectors, it was concluded that these velocities may be low relative to those needed to produce very stable twophase flow. These velocities could be increased to the desired levels by replacing all hoses on the coal delivery system with smaller ID hoses. Increasing carrier line velocities this way assumes that the carrier air and coal mass flow rates can be kept constant.

It was recognized that keeping the carrier air flow rate constant may not be possible, because of the supply pressure limitation of the carrier air compressor. A small change in hose ID can significantly increase the pressure drop over the delivery system lines. The first option considered was to rent a higher pressure compressor to ensure that sufficient pressure would be available to achieve the carrier air flow rates desired. Since it would take time to acquire and install a rental compressor system, it was decided to modify the coal delivery system hoses to experimentally determine what coal delivery flow conditions could be achieved with the present carrier air compressor.

Results from test SL2-2 demonstrated that the present carrier air compressor cannot supply the pressure head needed to maintain proper carrier air flow. Either a higher pressure compressor system or a high pressure air tube trailer 
will be rented. A permanent higher pressure carrier air supply will not be installed until it has been demonstrated that this approach corrects the char problem.

\subsubsection{Helium-Neon Laser Diagnostic Addition}

As previously mentioned, a new diagnostic was added to the system just prior to test run CR1-3, namely a He-Ne laser extinction diagnostic. This diagnostic was installed in the exhaust duct downstream of the lean-burn/ quench combustor. This diagnostic provides a real-time measure of exhaust duct particle loading by monitoring the decrease in the power of a low power He-Ne laser beam passed through the exhaust gas stream (normal to the exhaust gas flow direction). The laser beam enters and leaves the exhaust duct via optical windows. The exit beam power is measured via a photo diode detector. Reference power levels are acquired before and after the coal combustion segment of a test run. During coal combustion, the laser beam power monitored by the photo diode will decrease due to light scattering by the particles present in the exhaust gas stream. The natural logarithm of the ratio of the decreased laser beam power (when scattering occurs) to the reference power level (no scattering occurring) provides a measure of the number density of particles in the exhaust gas stream, which can be correlated with exhaust gas particle loading (i.e., mass flow rate of particles in the exhaust gas stream).

Since the extinction diagnosis has a frequency response of order $10 \mathrm{kHz}$, this diagnostic was installed primarily to determine if exhaust char is being produced on a continuous basis or whether there exists some periodic structure to char production. Periodic, unsteady char production may suggest that the coal/air injection jets in the primary zone may be oscillating spatially. If this occurs, the coal/air jets may be bending downward toward the exit nozzle of the primary zone, thereby sending coal directly to the exit of the primary zone, rather than upward into the toroidal vortex in the dome of the primary zone. The decrease in burn-out time due to this phenomena could cause char production. If steady-state char production is detected, other types of phenomena must be considered that may result in the production of char, such as biased coal injection. Biased coal injection occurs when the coal flow 
rates supplied to each of the four primary zone coal/air injectors differ. This can cause different regions of the primary zone to have different stoichiometries, thus producing char locally. It is important, therefore, to determine if the char production is steady or unsteady in order to begin isolating the source of the problem.

The extinction diagnostic serves several other purposes also, making this diagnostic a valuable asset. If it is assumed that the particle size distribution of the particles in the exhaust stream are very close from test run to test run, then a direct measure of the relative change in particle loading from one run to the next can be easily determined. In fact, the extinciton diagnostic can be calibrated based on the exhaust particle loadings derived from data from the particle collection probe sampling the exhaust gas stream. Thus, if a particle probe filter breaks during a run, exit particle loading data can still be acquired by information derived from the extinction diagnostic. It also supplies a real-time technique for determining whether operating paramater changes affect char production. It is now possible to see the effects of stoichiometry, coal carrier gas flow rate, etc., changes on char production.

\subsection{Ames Laboratory Alkali Testing.}

In June 1991, the last shipment of the Ames alkali probe components was received. At the beginning of this reporting period an inventory of all the materials and parts needed for the Ames alkali probe was made. It was determined that Textron had everything needed to assemble the Ames probe. It was estimated that it would take one man-month to put this system together.

As of the end of this reporting period installation of the Ames probe system was still in process.

2.3 Update of Reference System Definition. A revised topical report on an update of the coal-fired combustion turbine combined cycle and the effect of precombustion coal cleaning on the cost of electricity was issued to METC during this reporting period. 

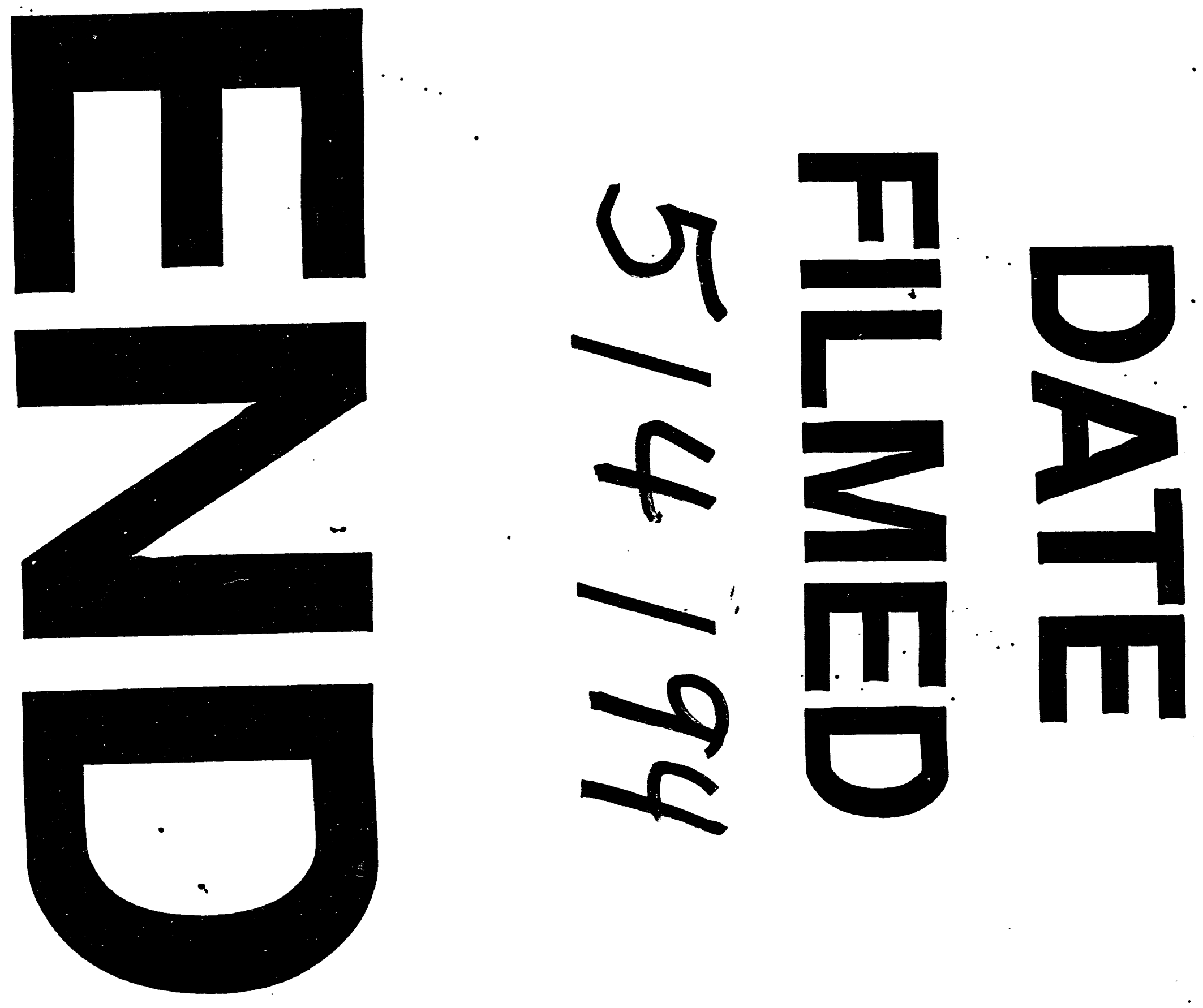


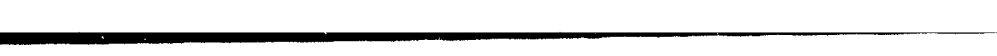

. 